\title{
Women's experiences of planning a vaginal birth after caesarean in different models of maternity care in Australia
}

\author{
Hazel Keedle ${ }^{1 *}$ D, Lilian Peters ${ }^{1,2}$, Virginia Schmied ${ }^{1}$, Elaine Burns ${ }^{1}$, Warren Keedle ${ }^{3}$ and Hannah Grace Dahlen ${ }^{1}$
}

\begin{abstract}
Background: Vaginal birth after caesarean (VBAC) is a safe mode of birth for most women but internationally VBAC rates remain low. In Australia women planning a VBAC may experience different models of care including continuity of care (CoC). There are a limited number of studies exploring the impact and influence of $\mathrm{CoC}$ on women's experiences of planning a VBAC. Continuity of care (CoC) with a midwife has been found to increase spontaneous vaginal birth and decrease some interventions. Women planning a VBAC prefer and benefit from CoC with a known care provider. This study aimed to explore the influence, and impact, of continuity of care on women's experiences when planning a VBAC in Australia.

Methods: The Australian VBAC survey was designed and distributed via social media. Outcomes and experiences of women who had planned a VBAC in the past 5 years were compared by model of care. Standard fragmented maternity care was compared to continuity of care with a midwife or doctor.

Results: In total, 490 women completed the survey and respondents came from every State and Territory in Australia. Women who had $\mathrm{CoC}$ with a midwife were more likely to feel in control of their decision making and feel their health care provider positively supported their decision to have a VBAC. Women who had CoC with a midwife were more likely to have been active in labour, experience water immersion and have an upright birthing position. Women who received fragmented care experienced lower autonomy and lower respect compared to CoC.

Conclusion: This study recruited a non-probability based, self-selected, sample of women using social media. Women found having a VBAC less traumatic than their previous caesarean and women planning a VBAC benefited from CoC models, particularly midwifery continuity of care. Women seeking VBAC are often excluded from these models as they are considered to have risk factors. There needs to be a focus on increasing shared belief and confidence in VBAC across professions and an expansion of midwifery led continuity of care models for women seeking a VBAC.
\end{abstract}

Keywords: Vaginal birth after caesarean, VBAC, Continuity of care, Midwifery, Active birth, Waterbirth

\footnotetext{
* Correspondence: h.keedle@westernsydney.edu.au

'School of Nursing and Midwifery, Western Sydney University, Locked Bag

1797, Penrith, NSW 2751, Australia

Full list of author information is available at the end of the article
}

C C The Author(s). 2020 Open Access This article is licensed under a Creative Commons Attribution 4.0 International License, which permits use, sharing, adaptation, distribution and reproduction in any medium or format, as long as you give appropriate credit to the original author(s) and the source, provide a link to the Creative Commons licence, and indicate if changes were made. The images or other third party material in this article are included in the article's Creative Commons licence, unless indicated otherwise in a credit line to the material. If material is not included in the article's Creative Commons licence and your intended use is not permitted by statutory regulation or exceeds the permitted use, you will need to obtain permission directly from the copyright holder. To view a copy of this licence, visit http://creativecommons.org/licenses/by/4.0/ The Creative Commons Public Domain Dedication waiver (http://creativecommons.org/publicdomain/zero/1.0/) applies to the data made available in this article, unless otherwise stated in a credit line to the data. 


\section{Background}

Vaginal birth after caesarean (VBAC) can be a safe and satisfying birth option for women who have had a previous caesarean [1], but rates in Australia remain low (11\%) [2]. VBAC rates are quite high in countries such as Finland, Norway and The Netherlands (38-55\%) and low in Australia and the US (12\%) [2-4]. In Australia the vast majority of caesareans undertaken are due to repeat caesareans [2]. In New South Wales (NSW) the VBAC rate varies from $6 \%$ in private hospitals to $19 \%$ in public hospitals [5].

The Lancet series on caesarean section, published in 2018, recognised caesarean as a medical intervention with global disparity [6]. It has been described as an example of 'too little, too late and too much, too soon'; a term adopted to explain the poor quality maternal care in facilities with inadequate staff, training and infrastructure and over-medicalisation of births [7]. Interventions that may reduce unnecessary caesareans include antenatal education, training, implementation of evidence based guidelines, labour companionship, midwifery continuity of care $(\mathrm{CoC})$, midwife-led units, birth centre and homebirth and mandated second opinions [8].

In NSW, Australia, a progressive policy, Towards Normal Birth, was introduced in 2010 with targets to reduce caesareans, including increasing VBAC rates to greater than $60 \%$ by 2015 [9]. Despite these efforts, the NSW VBAC rate remains low at $14.9 \%$ and caesarean section rates have continued to increase in the past decade [5].

Research on VBAC focuses on decision making for women planning a next birth after caesarean (NBAC) [10-12] and on prediction scores for women's likelihood of having a VBAC [13-15], there is less qualitative research on women's experiences of planning a VBAC. Existing studies have found that women can be met with both helpful and hurtful attitudes from health providers, but the experience of having a VBAC can be triumphant and healing, which is consistently remembered years after the VBAC $[16,17]$.

There are known factors that can contribute to women having a VBAC, such as younger age, lower BMI, white ethnicity, higher education level, having a previous vaginal birth and having a previous VBAC $[14,15,18,19]$; however, the effect of the maternity model of care and clinician influences and attitudes has received less attention.

A recent qualitative study from Europe explored the maternity culture in high and low VBAC countries and found that clinicians in the high VBAC countries had a positive and pro-VBAC attitude, which encouraged women to choose VBAC, whereas in the countries with low VBAC rates clinicians held both pro and anti-VBAC views which negatively affected women who were seeking VBAC [20].
Both qualitative and quantitative studies have shown that having midwifery care can have a positive influence on VBAC rates without an increase in maternal or neonatal morbidity [21-23].

Continuity of care with a midwife has been found to increase spontaneous vaginal birth rates, and decrease preterm birth, caesareans, episiotomies, instrumental births and epidural rates $[24,25]$. The introduction of a midwifery model of care with a collaborative obstetrician in the USA increased VBAC rates by $8 \%$ according to a study by Rosenstein et al. (2015) [26] and a small randomised controlled trial (RCT) in China resulted in a VBAC rate of $87.5 \%$ for women who had midwifery $\mathrm{CoC}$ compared to $66.7 \%$ of women having standard antenatal care [22].

In Australia, women can access a variety of maternity care models, dependent on location and availability. Continuity of care with a midwife in a public hospital is growing as an option for women across Australia [27]. This option may also be available through privately practising midwives who offer homebirth or have visiting rights to public hospitals [28]. Women can also have $\mathrm{CoC}$ with a private obstetrician or general practitioner (GP)/ obstetrician and give birth in private hospitals, dependent on location, with $26 \%$ of women choosing this option in 2017 [2]. Fragmented standard antenatal care, which is accessed by the majority of women, involves receiving care from multiple midwives and doctors during pregnancy, labour and birth and in the postnatal period.

This paper reports on the quantitative third phase of a larger, three-phased exploratory sequential mixed methods study. The first phase was a published metaethnography of 20 qualitative papers exploring women's experiences of VBAC [23]. The overarching theme of the meta-ethnography was 'the journey from pain (previous caesarean) to power (VBAC)'. The second phase, published in 2019, was qualitative and focused on pregnant women who were planning a VBAC who made audio or video diary recordings, on a purpose build smartphone application, during pregnancy and were also interviewed 6 weeks after birth [17]. The second phase revealed four factors that influenced how women felt after their VBAC or repeat caesarean: having control; having confidence in themselves and in their health care providers; having a supportive relationship with a health care provider; and staying active in labour [17]. This third phase used the four factors as the framework for design, analysis and organisation of survey results, comparing the experiences of women who identified they had received $\mathrm{CoC}$ with a midwife (private / public), with a doctor (private / public / GP), with those who experienced standard, fragmented care. The aim of the third phase of the study was to explore the influence and 
impact of continuity of care on women's experiences when planning a VBAC in Australia, within the past 5 years.

\section{Methods}

A national Australian survey was undertaken as the last phase of a sequential exploratory mixed methods study. An explorative qualitative phase was first undertaken to explore the experiences of women planning a VBAC in Australia and this quantitative survey was designed to further test the findings from the qualitative phase [29].

\section{Survey development}

A survey was developed from data analysed during the qualitative phase of this mixed methods study. The first part of the survey gathered demographic data and focused on questions related to the model of care women experienced. Questions were based around 'four factors' that emerged from the narrative stories of women planning a VBAC in Australia, including control, confidence, relationship and active labour [17]. Examples of the questions asked in the survey, based on each factor can be found in the mixed methods integration table (Table 1).

The survey included two validated Canadian measures exploring decision making and respect: the Mother's Autonomy in Decision Making (MADM) scale [30] and the Mothers on Respect index (MORi) [31] (Table 5). The MADM scale has been further validated exploring 2051 women's experiences of different care providers [32] and both the MADM and MORi have been evaluated and found feasible and reliable in a study from The Netherlands [33]. The 7-item MADM scale explores the degree of autonomy in decision making care providers give to women, from the woman's perspective [32] and was included in the two factors control and confidence. The 14- item MORi scale measures respectful maternity care through interactions with primary maternity care providers [31] and was included to measure the factor

Table 1 Mixed methods approach to survey development from the 'four factors'

\begin{tabular}{|c|c|c|}
\hline Phase 2 Theme & Phase 2 Quote & Examples of survey questions \\
\hline $\begin{array}{l}\text { Control - how 'in control' the woman felt } \\
\text { over her decisions, choices and outcomes }\end{array}$ & $\begin{array}{l}\text { "because I think apart from that I was in control } \\
\text { the whole way. There was at no point somebody } \\
\text { said to me, "No, you can't do that, ... I think the } \\
\text { continuity of care, having this same midwife for } \\
\text { every single appointment, she stayed with me from } \\
\text { the moment I laboured until I went to recovery } \\
\text { and so that made a huge difference." (Arabelle, } \\
\text { PN, MGP). }\end{array}$ & $\begin{array}{l}\text { - Did you have a birth plan? } \\
\text { - Did your maternity care provider support all of } \\
\text { your birth plan? } \\
\text { - Did you feel in control of your decision making? } \\
\text { - MADM scores } \\
\text { - Birth trauma questions }\end{array}$ \\
\hline $\begin{array}{l}\text { Confidence - includes the woman's belief } \\
\text { in her ability to have a VBAC but also how } \\
\text { confident she felt her health care provider } \\
\text { was in her ability to have a VBAC }\end{array}$ & $\begin{array}{l}\text { "I found it really encouraging that she's, she agrees } \\
\text { with me and she's confident as well that I can get } \\
\text { a relatively medicine free VBAC which is awesome } \\
\text { because you don't often get that from many other } \\
\text { places, so that made me feel a bit better." (Bianca, } \\
\text { 38/40, PPM) }\end{array}$ & $\begin{array}{l}\text { - How confident did you feel in your body's } \\
\text { ability to have a VBAC? } \\
\text { - Do you feel your maternity care provider was } \\
\text { confident in your ability to have a VBAC during } \\
\text { your pregnancy? } \\
\text { - Do you feel your maternity care provider was } \\
\text { confident in your ability to have a VBAC during } \\
\text { labour and birth? } \\
\text { - Did your maternity care provider think you } \\
\text { should or should not schedule another } \\
\text { caesarean? } \\
\text { - MADM scores }\end{array}$ \\
\hline $\begin{array}{l}\text { Relationship - how respected and supported } \\
\text { she felt from her health care provider and the } \\
\text { quality and continuity of that support }\end{array}$ & $\begin{array}{l}\text { "I didn't really have an appointment with my } \\
\text { midwife as such, but l've been in contact with her } \\
\text { quite a bit over the last } 2 \text { days and I've spoken to } \\
\text { her for over } 1 / 2 \text { an hour today so in my eyes it's } \\
\text { pretty close to what you would do in an } \\
\text { appointment anyway." (Calista, 38/40, MGP) }\end{array}$ & $\begin{array}{l}\text { - On average, how long were your prenatal visits? } \\
\text { - Did you experience any positive support from } \\
\text { maternity care providers when planning a VBAC? } \\
\text { - Did you feel that your primary maternity care } \\
\text { provider protected you from negativity within } \\
\text { the health care team due to your birth choices? } \\
\text { - Did you receive any unhelpful or hurtful } \\
\text { comments from a maternity care provider } \\
\text { while planning a VBAC? } \\
\text { - MORi scores }\end{array}$ \\
\hline $\begin{array}{l}\text { Active labour - whether the woman was able } \\
\text { to stay active in labour, including minimising } \\
\text { interventions, and how this impacted her } \\
\text { experience }\end{array}$ & $\begin{array}{l}\text { "I had hot water like fall off on my back and that } \\
\text { was really it. I kind of just used water for the most } \\
\text { part, water and quietness" (Bianca, PN, PPM). }\end{array}$ & $\begin{array}{l}\text { - What position did you birth your baby? } \\
\text { - How active were you in labour? } \\
\text { - Did your maternity care provider encourage you } \\
\text { to be active or vocal in labour? } \\
\text { - When you were admitted to the hospital (or at } \\
\text { home) and had your first internal vaginal exam, } \\
\text { how many centimetres was your cervix dilated } \\
\text { (opened)? } \\
\text { - Did your maternity care provider try to induce } \\
\text { your labour? }\end{array}$ \\
\hline
\end{tabular}


relationship. Higher scores on the MADM indicate higher levels of autonomy (very low patient autonomy 7-15, low patient autonomy 16-24, moderate patient autonomy $25-33$, high patient autonomy 34-42). Higher scores on the MORi indicate higher levels of respect (very low respect $14-31$, low respect $32-49$, moderate respect 50-66, high respect 67-84). These measures have been evaluated as feasible, reliable and valid in Dutch and Canadian studies [30-33].

Ethics approval was obtained through the Western Sydney University Human Research ethics committee: No H11890.

\section{Pilot testing of the survey}

To support the feminist research principles used throughout this mixed methods study and described in Keedle et al. (2019) [17], it was imperative to involve potential survey participants in the co-design and pilot testing of the survey [34]. This was achieved using online cognitive focus groups [35].

Cognitive focus groups have developed from cognitive interviewing which aims to understand the responses of survey questions by analysing the comprehension, recall, decisions and judgement and response processes of targeted participants [35-38]. Recruitment for the focus groups included social media pregnancy and parenting groups where women were asked to contact the researcher if interested in testing the survey and participating in focus groups. Focus groups with 33 women were conducted online to allow for attendance of women across Australia through Zoom online conferencing [39]. One focus group was held during the day with five women attending and the other, with 16 women attending was held during the evening. Another 12 women who could not attend the online focus group sent written feedback regarding the survey questions.

The response from the focus group participants revealed that the survey had good face validity. Most of the suggested changes to the survey involved adding or changing options in questions, such as adding extra resources to lists and adding extra open text box questions. For example, one question added was focused on the type of caesarean scar as identified by a focus group participant. Current national guidelines recommend repeat caesarean for previous classical, inverted $\mathrm{T}$ or $\mathrm{J}$ uterine incisions due to increased uterine rupture rates [1, 40-43]. Through partnership and collaboration with women during the survey development phase, the final survey included questions designed and amended by women for women, which was important in order to adhere to feminist research principles [34].

The final survey consisted of 114 items with yes/no, Likert scales, specific options and open-ended questions. The sections of the survey were demographics, pregnancy and healthcare details and questions related to the four factors (including MADM and MORi). The online survey was developed and managed using Qualtrics software, Version 2019, Provo, UT, USA [44]. A copy of the survey is included in the supplementary files as supplementary file 1 .

\section{Recruitment of survey respondents}

This study recruited a non-probability based, selfselected, sample of women using social media. Participants were recruited through a short video explaining the survey and the eligibility criteria in a Facebook post, which included the online survey web link. The post was shared across social media platforms and in relevant consumer groups. Respondents were self-selected as they chose to participate (opt in) in the survey [45]. Two paid Facebook / Instagram adverts were released with the aim to reach potential participants who may have left or not be members of consumer groups. The adverts aimed at female gender, $18-45$ yrs. and living in Australia, resulted in 243 link clicks (directing straight to the survey) with the remaining respondents coming through the shared survey posts. The survey was live during the months of March to May 2019.

\section{Data analysis}

The data were analysed descriptively. Due to lack of normal distribution of total scores for the MADM and MORI, medians and interquartile range (IQR) were calculated. Statistical differences between the different $\mathrm{CoC}$ groups i.e. fragmented care (Frag), $\mathrm{CoC}$ with a Doctor (Dr), CoC with a Midwife (MW) and maternal characteristics were calculated by using chi-square tests, Kruskal Wallis tests, where appropriate. Data were analysed using SPSS (version 25). $P$-value $<0.05$ was considered as significant.

\section{Four factors metrics}

Based on modelling principles used for climate change analysis [46], each of the four factors (control, confidence, relationship and active labour) were related to the five questions from the survey that most represented this factor (see Table 1). These factors were plotted on a scale creating a representative subset. Within each of the four factors the mean for each $\mathrm{CoC}$ option was calculated to create a confidence measure in that factor. This creates a correlation of the confidence measure vs the $\mathrm{CoC}$ option within each factor (Fig. 1).

While the absolute value of this mean is not significant the slope of the line between the means for each model of care is significant. If the slope is positive (angled upwards) the higher $\mathrm{CoC}$ option has higher percentage values for that measured factor. The angle of the slope demonstrates the degree of variance between care 


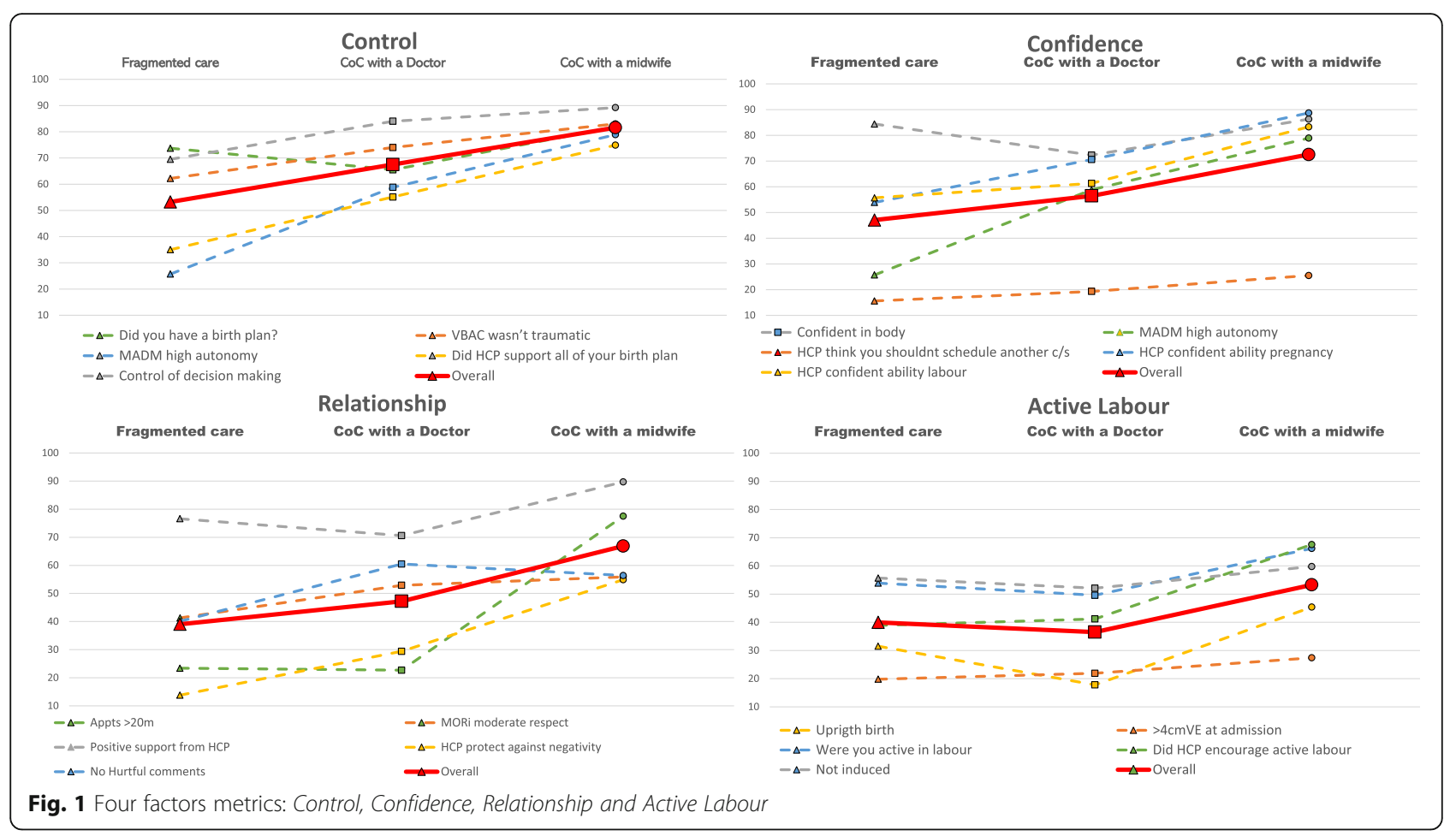

models. If the slope is negative (angled downwards) the $\mathrm{CoC}$ option on the lowest point has lower percentage values for that measured factor. Additionally, across each $\mathrm{CoC}$ option it can easily be seen which of the five metrics has the greatest deviation from the mean, therefore determining which metrics are having a significant impact (positive or negative) upon each of the four factors related to each CoC option. The final graph is an amalgamation of the four factors confidence measures which presents an overall picture of the combined four factors vs $\mathrm{CoC}$ options (Fig. 2).

\section{Results}

In total 543 women completed the survey. Of those, 53 women were excluded from the analyses due to missing data. In the present analyses 490 women were included. Women were from all States and Territories of Australia and were from urban, regional and remote Australia (Fig. 3). The majority of women described their ethnic background as $(n=381,78 \%)$ Australian and $1.8 \%$ of women $(n=9)$ identified as Aboriginal and/or Torres Strait Islanders. In total $42 \%$ women $(n=204)$ received CoC with a midwife, $24 \%(n=119) \mathrm{CoC}$ with a doctor, and $34 \%(n=167)$ received fragmented care.

The majority of women were aged between 25 and 34 years, with slightly more women over 40 yrs. accessing $\mathrm{CoC}$ with a midwife, although this wasn't statistically significant. Most women had a combined annual family income of $>\$ 100,000$ AUD (50\%) and this was statistically significantly higher in the women that had $\mathrm{CoC}$ with a doctor. Although most births occurred in hospital, $31 \%$ of women who had $\mathrm{CoC}$ with a midwife had births outside of the hospital (home/birth centre). One woman stated she had $\mathrm{CoC}$ with a doctor and then gave birth at home with a midwife, the care provider was identified as a GP/Obstetrician, she was placed in the $\mathrm{CoC}$ with a doctor group. The majority of women had a lower uterine transverse scar from their previous caesarean (94-96\% in the all CoC groups) (Table 2).

\section{Having control}

The first of the four factors, having control, explores how 'in control' the woman felt over her decisions, choices and outcomes. Decision making when planning a VBAC, developing a birth plan, and experiencing birth trauma (both previous and current) were explored in this factor. Just over two thirds of women reported their previous caesarean as a traumatic experience (69\%). For women who had a VBAC, $17 \%$ found the VBAC traumatic; and this was statistically significantly more likely to be associated with fragmented care (26\%) (Table 3). Just over half of women (53\%) who had a repeat caesarean after planning a VBAC found the repeat caesarean traumatic and $\mathrm{CoC}$ with a midwife or doctor made no significant difference.

When asked a single question on how in control of their decision making they felt, more women who had $\mathrm{CoC}$ with a midwife felt in control of their decision making (Frag70\%, Dr84\%, MW89\% $p=\leq 0.001$ ) and more women had developed a birth plan if they had $\mathrm{CoC}$ with 


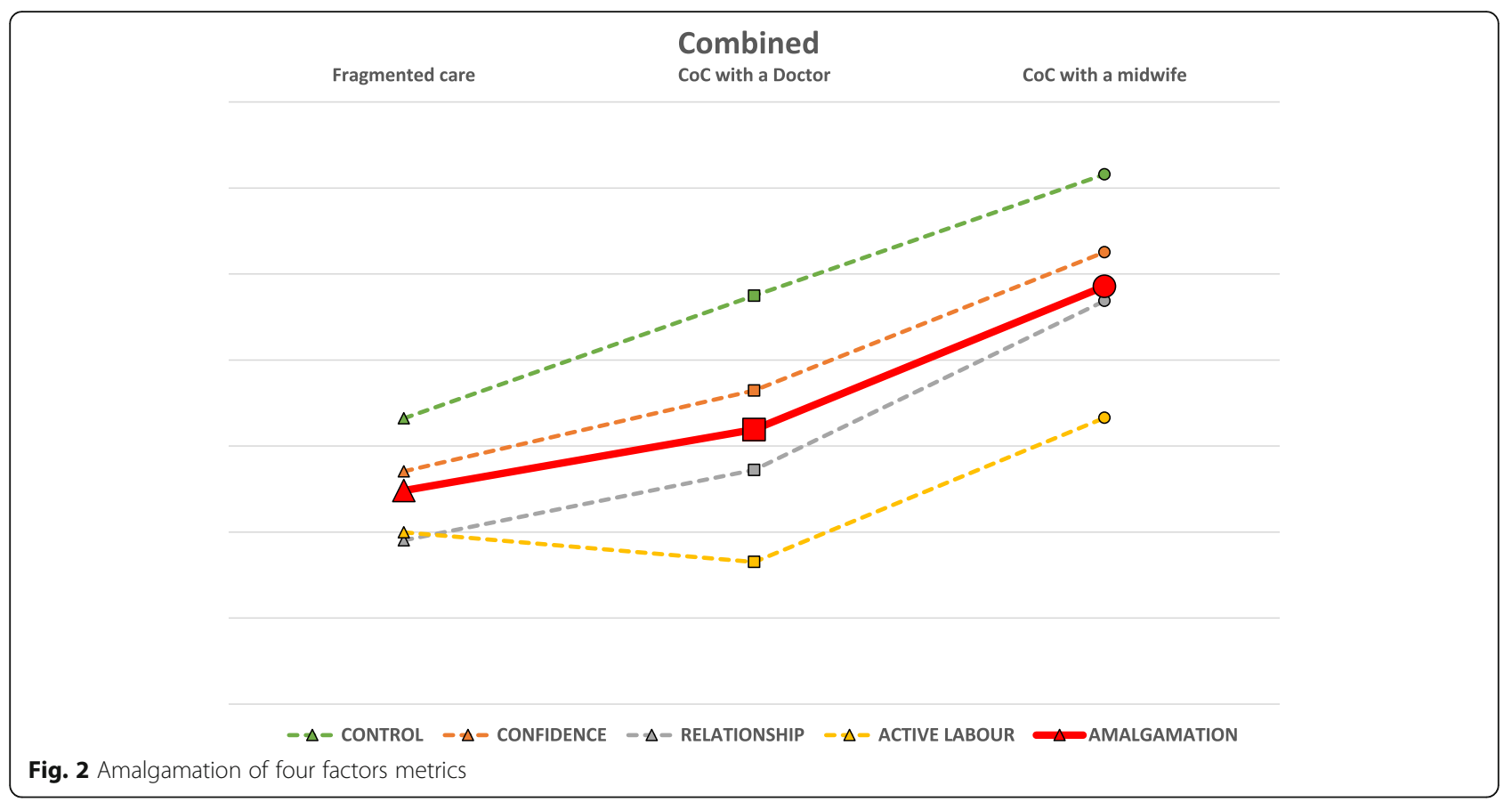

a midwife (Frag74\%, Dr66\%, MW82\% $p=0.001$ ) (Table 4).

\section{Having confidence}

Confidence was identified previously as one of the four important factors that impacts how a woman feels after her birthing experience. It includes the woman's belief in her ability to have a VBAC and also how confident her health care provider was in her ability to have a VBAC. A high proportion of women reported that they were confident in their body's ability to have a VBAC. Differences were found when asked if they felt their health care provider was confident in their ability to have a VBAC during their pregnancy (Frag54\%, Dr71\%, MW89\% $\mathrm{p}=\leq 0.001$ ) or during labour (Frag56\%, Dr61\%, MW83\% $p=\leq 0.001$ ) (Table 4).

\section{MADM \& MORi scores}

In our population the MADM-scores ranged from 28 to 42. Women who had $\mathrm{CoC}$ with a midwife showed higher scores on the MADM, compared with the other CoCgroups and this was statistically significantly (Table 5). The MORi-scores ranged from 42 to 61 . Women who had $\mathrm{CoC}$ with a midwife showed higher scores on the MORi, compared with the other CoC-groups and this was statistically significant (Table 5).

\section{Having a relationship}

The factor Having a relationship explores the relationship women have with their health care provider and highlights differences between $\mathrm{CoC}$ providers. Women experienced more support when having $\mathrm{CoC}$ from a midwife (Frag77\%, Dr71\%, MW90\% $p=\leq 0.001$ ) and half of the women who had fragmented care received hurtful comments from health care providers (Frag51\%, Dr24\%, MW35\% $p=\leq 0.001$ ). For the women who did receive $\mathrm{CoC}(n=323)$ more women felt happy with their continuity of care experience if they had a midwife (Dr91\%, MW97\% $p=0.028$ ) (Table 4).

Significant differences were found in the length of time taken for antenatal appointments across different $\mathrm{CoC}$ options. The majority of women's appointments for fragmented care and $\mathrm{CoC}$ with a doctor were between 10 and 15 min (Frag35\%, Dr39\%, MW7\% $p=\leq 0.001$ ), while the majority of appointments with a midwife were between 30 and $60 \mathrm{~min}$ (Frag4\%, Dr4\%, MW29\% $p=\leq 0.001$ ) (Fig. 4).

\section{Active labour}

The fourth factor Active labour looks at whether the woman was able to stay active during labour and how this impacted on her experience. In this study, we explored: the active labour resources that women accessed; how they stayed active in labour; and labour and birth outcomes.

During labour, women identified position changes as the most common way to remain active in labour (Frag75\%, Dr66\%, MW81\%) followed by breathing techniques (Frag59\%, Dr50\%, MW61\%) and then using the shower (Frag35\%, Dr29\%, MW48\%) (Table 6).

Nitrous oxide was the most common pain medication used in labour (Frag44\%, Dr37\%, MW36\%) followed by epidural (Frag22\%, Dr21\%, MW17\%). More women who had $\mathrm{CoC}$ with a midwife used no pain relief (Frag19\%, 


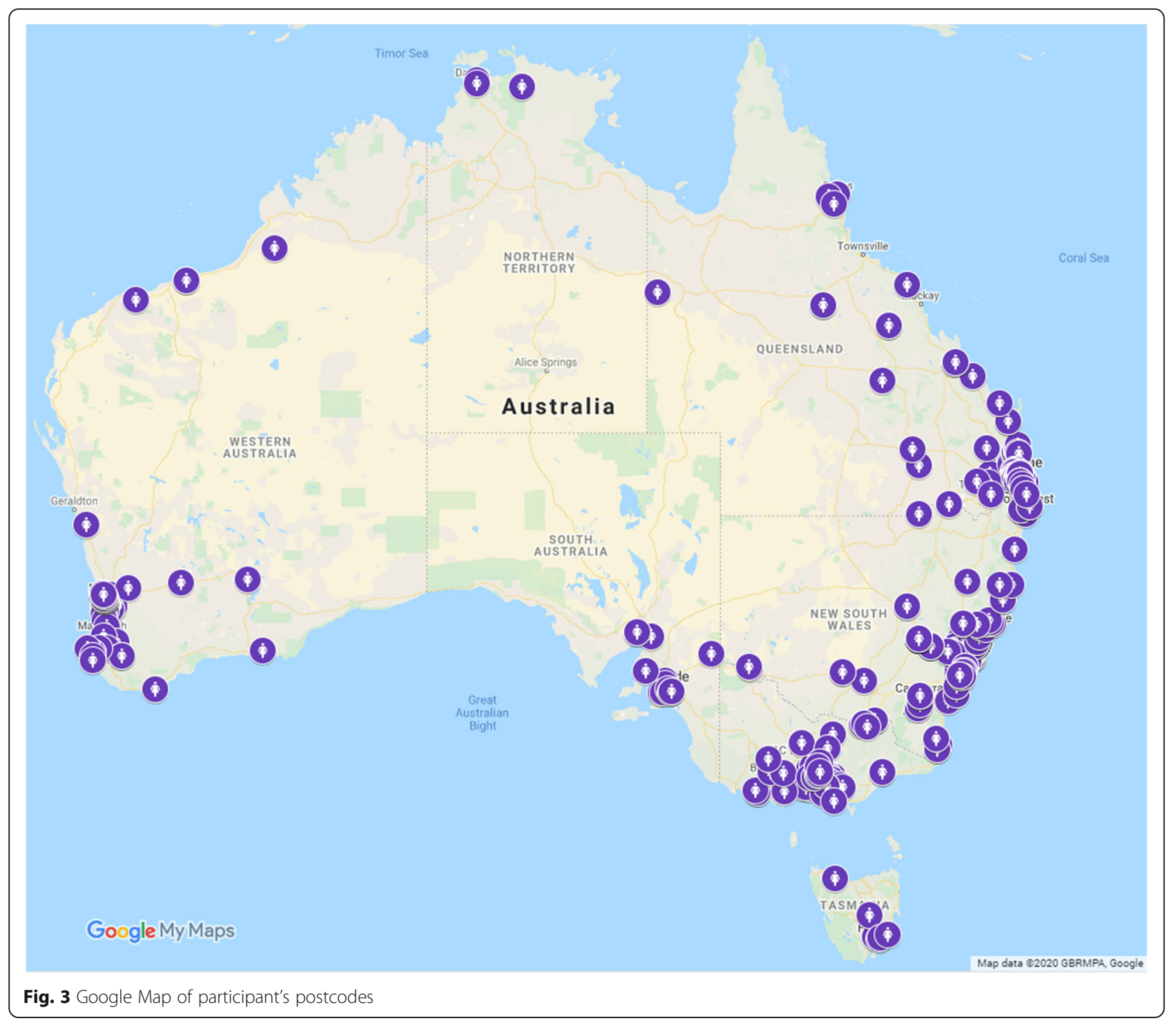

Dr13\%, MW35\%) (Table 6). As these questions allowed for more than one option in the list of answers, statistical significance couldn't be calculated.

Although this survey was open to women who planned a VBAC, regardless of birth outcome, the majority of women who completed the survey had experienced a VBAC (Frag67\%, Dr61\%, MW69\%) giving an average VBAC rate of $66 \%$. There was a statistically significant difference between the different $\mathrm{CoC}$ options regarding scheduled caesareans before labour (Frag7\%, Dr11\%, MW1\%, $p=0.002$ ), although only two women who had $\mathrm{CoC}$ with a midwife ended up with a caesarean before labour.

For women who had a VBAC $(n=325)$, they were more likely to have an upright birth if they had $\mathrm{CoC}$ with a midwife (Frag32\%, Dr18\%, MW46\%, $p=\leq 0.001)$ and to have a waterbirth if they had
CoC with a midwife (Frag5\%, Dr3\%, MW21\%, $p=\leq 0.001)$.

\section{Four factors}

The four factors metrics identify a greater percentage of women who had positive outcomes in relation to each factor when they had $\mathrm{CoC}$ with a midwife. In the factor control, there were higher percentages of women who had written a birth plan, had their HCP support all their birth plan, felt in control of their decision making, had higher autonomy with decision making and didn't have a traumatic VBAC when accessing $\mathrm{CoC}$ with a midwife. In the confidence factor we asked whether they were: confident in their body; confident in their HCP during pregnancy and labour; didn't have a $\mathrm{HCP}$ who thought they should schedule a caesarean; and level of autonomy. 
Table 2 Participant demographics, types of previous caesarean scar and place of birth

\begin{tabular}{|c|c|c|c|c|c|}
\hline & $\begin{array}{l}\text { TOTAL INCLUDED } \\
\text { POPULATION } \\
\begin{array}{l}N=490 \\
N(\%)\end{array}\end{array}$ & $\begin{array}{l}\text { Fragmented } \\
\text { care } \\
n=167(34.1 \%) \\
n(\%)\end{array}$ & $\begin{array}{l}\text { CoC with a } \\
\text { Doctor } \\
n=119(24.3 \%) \\
n(\%)\end{array}$ & $\begin{array}{l}\text { CoC with a } \\
\text { Midwife } \\
n=204(41.6 \%) \\
n(\%)\end{array}$ & $\begin{array}{l}\text { Statistical } \\
\text { differences } \\
p \text { value }\end{array}$ \\
\hline Maternal age (in years) & & & & & 0.29 \\
\hline $18-24$ & $33(6.7)$ & $11(6.6)$ & $4(3.4)$ & $18(8.8)$ & \\
\hline $25-34$ & $331(67.6)$ & $117(70.1)$ & $86(72.3)$ & $128(62.7)$ & \\
\hline $35-39$ & $108(22)$ & $33(19.8)$ & $27(22.7)$ & $48(23.5)$ & \\
\hline$>40$ & $18(3.7)$ & $6(3.6)$ & $2(1.7)$ & $10(4.9)$ & \\
\hline Country of birth & & & & & 0.93 \\
\hline Australia & $419(85.5)$ & $140(83.8)$ & $106(89.1)$ & $173(84.8)$ & \\
\hline New Zealand & $13(2.6)$ & $7(4.2)$ & $1(0.8)$ & $5(2.5)$ & \\
\hline UK & $18(3.7)$ & $8(4.8)$ & $4(3.4)$ & $6(2.9)$ & \\
\hline North America \& Canada & $10(2)$ & $4(2.4)$ & $2(1.7)$ & $4(2)$ & \\
\hline South America & $8(1.6)$ & $2(1.2)$ & $1(0.8)$ & $5(2.5)$ & \\
\hline Europe \& Russia & $10(2)$ & $2(1.2)$ & $3(2.5)$ & $5(2.5)$ & \\
\hline Asia \& Pacific & $6(1.2)$ & $2(1.2)$ & $1(0.8)$ & $3(1.5)$ & \\
\hline Africa & $6(1.2)$ & $2(1.2)$ & $1(0.8)$ & $3(1.5)$ & \\
\hline Combined annual family income & & & & & $\leq 0.001$ \\
\hline$<40,000$ & $19(3.9)$ & $11(6.6)$ & $1(0.8)$ & $7(3.4)$ & \\
\hline$\$ 40,000-\$ 59,999$ & $45(9.2)$ & $19(11.4)$ & $8(6.7)$ & $18(8.8)$ & \\
\hline$\$ 60,000-\$ 79,999$ & $73(14.9)$ & $33(19.8)$ & $12(10.1)$ & $28(13.7)$ & \\
\hline$\$ 80,000-\$ 99,999$ & $83(16.9)$ & $34(20.4)$ & $12(10.1)$ & $37(18.1)$ & \\
\hline$>\$ 100,000$ & $242(49.4)$ & $57(34.1)$ & $79(66.4)$ & $106(52)$ & \\
\hline Prefer not to answer & $27(5.5)$ & $13(7.8)$ & $7(5.9)$ & $7(3.4)$ & \\
\hline Missing & $1(0.2)$ & $0(0)$ & $0(0)$ & $1(0.5)$ & \\
\hline State or Territory of VBAC & & & & & 0.21 \\
\hline NSW & $175(35.7)$ & $58(34.7)$ & $42(35.3)$ & $75(36.8)$ & \\
\hline QLD & $92(18.8)$ & $28(16.8)$ & $22(18.5)$ & $42(20.6)$ & \\
\hline $\mathrm{VIC}$ & $79(16.1)$ & $34(20.4)$ & $20(16.8)$ & $25(12.3)$ & \\
\hline $\mathrm{ACT}$ & $8(1.6)$ & $2(1.2)$ & $1(0.8)$ & $5(2.5)$ & \\
\hline TAS & $6(1.2)$ & $2(1.2)$ & $4(3.4)$ & $0(0.0)$ & \\
\hline WA & $89(18.2)$ & $28(16.8)$ & $19(16)$ & $42(20.6)$ & \\
\hline SA & $27(5.5)$ & $9(5.4)$ & $8(6.7)$ & $10(4.9)$ & \\
\hline NT & $4(0.8)$ & $3(1.8)$ & $0(0.0)$ & $1(0.5)$ & \\
\hline Missing & $10(2)$ & $3(1.8)$ & $3(2.5)$ & $4(2)$ & \\
\hline Highest level of education & & & & & 0.002 \\
\hline Year 10 or School Certificate & $25(5.1)$ & $13(7.8)$ & $7(5.9)$ & $5(2.5)$ & \\
\hline Year 12 or Higher School Certificate & $64(13.1)$ & $32(19.2)$ & $13(10.9)$ & $19(9.3)$ & \\
\hline TAFE or Diploma & $108(22)$ & $43(25.7)$ & $22(18.5)$ & $43(21.1)$ & \\
\hline Undergraduate or University Qualification & $178(36.3)$ & $51(30.5)$ & $41(34.5)$ & $86(42.2)$ & \\
\hline Post-graduate (eg. Graduate Diploma, Masters, PhD) & $115(23.5)$ & $28(16.8)$ & $36(30.3)$ & $51(25)$ & \\
\hline Ethnicity & & & & & 0.70 \\
\hline Australian & $381(77.8)$ & $133(79.6)$ & $95(79.8)$ & $153(75)$ & \\
\hline Aboriginal and/or Torres Strait Islander & $9(1.8)$ & $4(2.4)$ & $2(1.7)$ & $3(1.5)$ & \\
\hline New Zealander / Maori & $15(3.1)$ & $7(4.2)$ & $1(0.8)$ & $7(3.4)$ & \\
\hline
\end{tabular}


Table 2 Participant demographics, types of previous caesarean scar and place of birth (Continued)

\begin{tabular}{|c|c|c|c|c|c|}
\hline & $\begin{array}{l}\text { TOTAL INCLUDED } \\
\text { POPULATION } \\
N=490 \\
N(\%)\end{array}$ & $\begin{array}{l}\text { Fragmented } \\
\text { care } \\
n=167(34.1 \%) \\
n(\%)\end{array}$ & $\begin{array}{l}\text { CoC with a } \\
\text { Doctor } \\
n=119(24.3 \%) \\
n(\%)\end{array}$ & $\begin{array}{l}\text { CoC with a } \\
\text { Midwife } \\
n=204(41.6 \%) \\
n(\%)\end{array}$ & $\begin{array}{l}\text { Statistical } \\
\text { differences } \\
p \text { value }\end{array}$ \\
\hline European & $48(9.8)$ & $14(8.4)$ & $12(10.1)$ & $22(10.8)$ & \\
\hline Middle Eastern & $6(1.2)$ & $2(1.2)$ & $1(0.8)$ & $3(1.5)$ & \\
\hline Asian & $7(1.4)$ & $2(1.2)$ & $3(2.5)$ & $2(1)$ & \\
\hline Americas & $14(2.9)$ & $3(1.8)$ & $3(2.5)$ & $8(3.9)$ & \\
\hline African & $2(0.4)$ & $1(0.6)$ & $0(0)$ & $1(0.5)$ & \\
\hline Other & $6(1.2)$ & $0(0)$ & $1(0.8)$ & $5(2.5)$ & \\
\hline Missing & $2(0.4)$ & $1(0.6)$ & $1(0.8)$ & $0(0)$ & \\
\hline Type of caesarean scar & & & & & 0.75 \\
\hline Lower uterine transverse & $465(94.9)$ & $160(95.8)$ & $114(95.8)$ & $191(93.6)$ & \\
\hline Classical & $10(2)$ & $3(1.8)$ & $1(0.8)$ & $6(2.9)$ & \\
\hline Inverted T & $5(1)$ & $2(1.2)$ & $1(0.8)$ & $2(1)$ & \\
\hline Low vertical & $2(0.4)$ & $0(0)$ & $0(0)$ & $2(1)$ & \\
\hline Upright T & $1(0.2)$ & $0(0)$ & $0(0)$ & $1(0.5)$ & \\
\hline Lower uterine extended & $5(1.0)$ & $1(0.6)$ & $2(1.7)$ & $2(1)$ & \\
\hline Place of birth if VBAC & & & & & $\leq 0.001$ \\
\hline At home freebirth & $8(2.5)$ & $6(5.4)$ & $0(0)$ & $2(1.4)$ & \\
\hline At home with midwife & $41(12.6)$ & $1(0.9)$ & $1(1.4)$ & $39(27.5)$ & \\
\hline Birth centre & $6(1.8)$ & $2(1.8)$ & $0(0)$ & $4(2.8)$ & \\
\hline Hospital & $269(82.5)$ & $102(91.9)$ & $70(97.2)$ & $96(67.6)$ & \\
\hline Accidental homebirth / on way to hospital & $1(0.3)$ & $0(0)$ & $0(0)$ & $1(0.7)$ & \\
\hline Missing & 1 & $0(0)$ & $1(1.4)$ & $0(0)$ & \\
\hline
\end{tabular}

Women who had $\mathrm{CoC}$ with a midwife reflected higher percentages in all five questions relating to confidence. In relationship there were higher percentages of: women who had appointments lasting over $20 \mathrm{~min}$ in duration; received positive support and felt their $\mathrm{HCP}$ protected them from negativity from other $\mathrm{HCPs}$ when they received $\mathrm{CoC}$ with a midwife. Finally, in the factor active labour, there were higher percentages of women who: had an active labour; were encouraged to be active in labour by their HCP; were more than $4 \mathrm{~cm}$ dilated when admitted to hospital in labour; and had an upright birth when they had $\mathrm{CoC}$ with a midwife.

Table 3 Birth trauma

\begin{tabular}{|c|c|c|c|c|c|c|}
\hline & & $\begin{array}{l}\text { TOTAL INCLUDED } \\
\text { POPULATION } \\
\begin{array}{l}N=490 \\
N(\%)\end{array}\end{array}$ & $\begin{array}{l}\text { Fragmented } \\
\text { care } \\
n=167(34.1) \\
n(\%)\end{array}$ & $\begin{array}{l}\text { CoC with a } \\
\text { Doctor } \\
n=119(24.3) \\
n(\%)\end{array}$ & $\begin{array}{l}\text { CoC with a } \\
\text { midwife } \\
n=204 \text { (41.6) } \\
n(\%)\end{array}$ & $\begin{array}{l}\text { Statistical } \\
\text { differences } \\
p \text { value }\end{array}$ \\
\hline \multicolumn{7}{|l|}{ Birth Trauma } \\
\hline \multicolumn{7}{|l|}{ Had a VBAC } \\
\hline Was your previous $\mathrm{c} / \mathrm{s}$ traumatic? & Yes & $223(68.6)$ & $73(65.8)$ & $40(54.8)$ & $110(78)$ & 0.018 \\
\hline \multicolumn{7}{|l|}{ Had a VBAC } \\
\hline Was this VBAC traumatic? & Yes & $56(17.2)$ & $29(26.1)$ & $12(16.4)$ & 15 (10.6) & 0.015 \\
\hline \multicolumn{7}{|l|}{ Had a repeat caesarean } \\
\hline Was your previous $\mathrm{c} / \mathrm{s}$ traumatic? & Yes & $65(67)$ & $28(77.8)$ & $15(57.7)$ & $22(62.9)$ & 0.5 \\
\hline \multicolumn{7}{|l|}{ Had a repeat caesarean } \\
\hline Was this $\mathrm{c} / \mathrm{s}$ traumatic? & Yes & $51(52.6)$ & $24(66.7)$ & $11(42.3)$ & $16(45.7)$ & 0.3 \\
\hline
\end{tabular}


Table 4 Control, Confidence \& Relationship

\begin{tabular}{|c|c|c|c|c|c|}
\hline & $\begin{array}{l}\text { TOTAL INCLUDED } \\
\text { POPULATION } \\
N=490 \\
N(\%)\end{array}$ & $\begin{array}{l}\text { Fragmented } \\
\text { care } \\
n=167(34.1) \\
n(\%)\end{array}$ & $\begin{array}{l}\text { CoC with a } \\
\text { Doctor } \\
n=119(24.3) \\
n(\%)\end{array}$ & $\begin{array}{l}\text { CoC with a } \\
\text { Midwife } \\
n=204(41.6) \\
n(\%)\end{array}$ & $\begin{array}{l}\text { Statistical } \\
\text { differences } \\
p \text { value }\end{array}$ \\
\hline \multicolumn{6}{|l|}{ Control } \\
\hline Control of decision making Yes & $398(81.2)$ & $116(69.5)$ & $100(84)$ & $182(89.2)$ & $\leq 0.001$ \\
\hline Did you write or think about a birth plan? Yes & $369(75.1)$ & $123(73.7)$ & $78(65.5)$ & $167(81.9)$ & 0.01 \\
\hline Did HCP support all of your birth plan Yes & $211(57.3)$ & $43(35)$ & $43(55.1)$ & $125(74.9)$ & $\leq 0.001$ \\
\hline \multicolumn{6}{|l|}{ Confidence } \\
\hline HCP confident ability pregnancy Yes & $355(72.4)$ & $90(53.9)$ & $84(70.6)$ & $181(88.7)$ & $\leq 0.001$ \\
\hline HCP confident ability labour Yes & $336(68.6)$ & $93(55.7)$ & $73(61.3)$ & $170(83.3)$ & $\leq 0.001$ \\
\hline Confident in body Yes & $403(82.2)$ & $141(84.4)$ & $86(72.3)$ & $176(86.3)$ & 0.36 \\
\hline \multicolumn{6}{|l|}{ Relationship } \\
\hline HCP think you should schedule another $\mathrm{c} / \mathrm{s}$ Yes & $176(35.9)$ & $99(59.3)$ & $37(31.1)$ & 40 (19.6) & $\leq 0.001$ \\
\hline Happy with CoC (323) Yes & $305(94.4)$ & N/A & $108(90.8)$ & $197(96.6)$ & 0.03 \\
\hline Positive support from HCP Yes & $395(80.6)$ & $128(76.6)$ & $84(70.6)$ & $183(89.7)$ & $\leq 0.001$ \\
\hline Hurtful comments Yes & $186(38)$ & $85(50.9)$ & $29(24.4)$ & $72(35.3)$ & $\leq 0.001$ \\
\hline
\end{tabular}

The amalgamation of all four factors in Fig. 2, demonstrates the impact of the factors compared across $\mathrm{CoC}$ options. This shows that $\mathrm{CoC}$ with a midwife has higher levels across all four factors and that $\mathrm{CoC}$ with a doctor also results in higher scores when compared with fragmented care, with one exception: active labour.

\section{Discussion}

Four hundred and ninety women who had planned a VBAC in the past 5 years responded to and completed the survey. The aim of this study was to explore the differences in these women's experiences under three common models of care in Australia: $\mathrm{CoC}$ with a midwife; $\mathrm{CoC}$ with a doctor; and fragmented maternity care. The framework made up of four factors, developed previously [17], was used to analyse and critique the experiences of these women planning a VBAC and will be used to frame the discussion.

\section{Control}

Over two thirds of women in the survey reported their previous caesarean was a traumatic experience. There is mounting international concern about the mistreatment of women during childbirth, and this includes poor rapport between women and providers, a lack of respect and lack of informed consent $[47,48]$. Emergency caesarean has been identified as a risk factor for postnatal PTS/D development [49]. Meta-ethnographic reviews have found that many women want the opportunity to birth vaginally and want to be treated with respect and care by maternity care providers [50]. Feeling a lack of control and being treated inhumanely contributes to having a traumatic birth experience [51]. In this study $17 \%$ of women found having a VBAC traumatic compared with $53 \%$ of women stating their repeat caesarean section was a traumatic experience. More than $88 \%$ of women found having a VBAC had a positive impact on their physical and emotional wellbeing, in the feelings they had about their body, their ability to be a mother and as an advocate for vaginal birth. This supports previous research on VBAC as generally being a healing, and less traumatic experience for women compared to caesarean $[16,23,52]$.

Table 5 Median scores of autonomy (MADM) and respect (MORi)

\begin{tabular}{|c|c|c|c|c|c|}
\hline & $\begin{array}{l}\text { TOTAL INCLUDED POPULATION } \\
N=490 \\
\text { Median (IQR) }\end{array}$ & $\begin{array}{l}\text { Fragmented care } \\
n=167(34.1 \%) \\
\text { Median (IQR) }\end{array}$ & $\begin{array}{l}\text { CoC with a Doctor } \\
n=119(24.3 \%) \\
\text { Median (IQR) }\end{array}$ & $\begin{array}{l}\text { CoC with a Midwife } \\
n=204(41.6 \%) \\
\text { Median (IQR) }\end{array}$ & $\begin{array}{l}\text { Statistical differences } \\
p \text { value }\end{array}$ \\
\hline \multicolumn{6}{|l|}{ MEASURES } \\
\hline $\begin{array}{l}\text { Mothers on Decision } \\
\text { Making }\end{array}$ & $36(28-42)$ & $28(18-35)$ & $37(29-42)$ & $41(35-42)$ & $\leq 0.001$ \\
\hline $\begin{array}{l}\text { Mothers on Respect } \\
\text { index }\end{array}$ & $53(42-61)$ & $50(41-57)$ & $53(41-60)$ & $55(45-62)$ & 0.02 \\
\hline
\end{tabular}




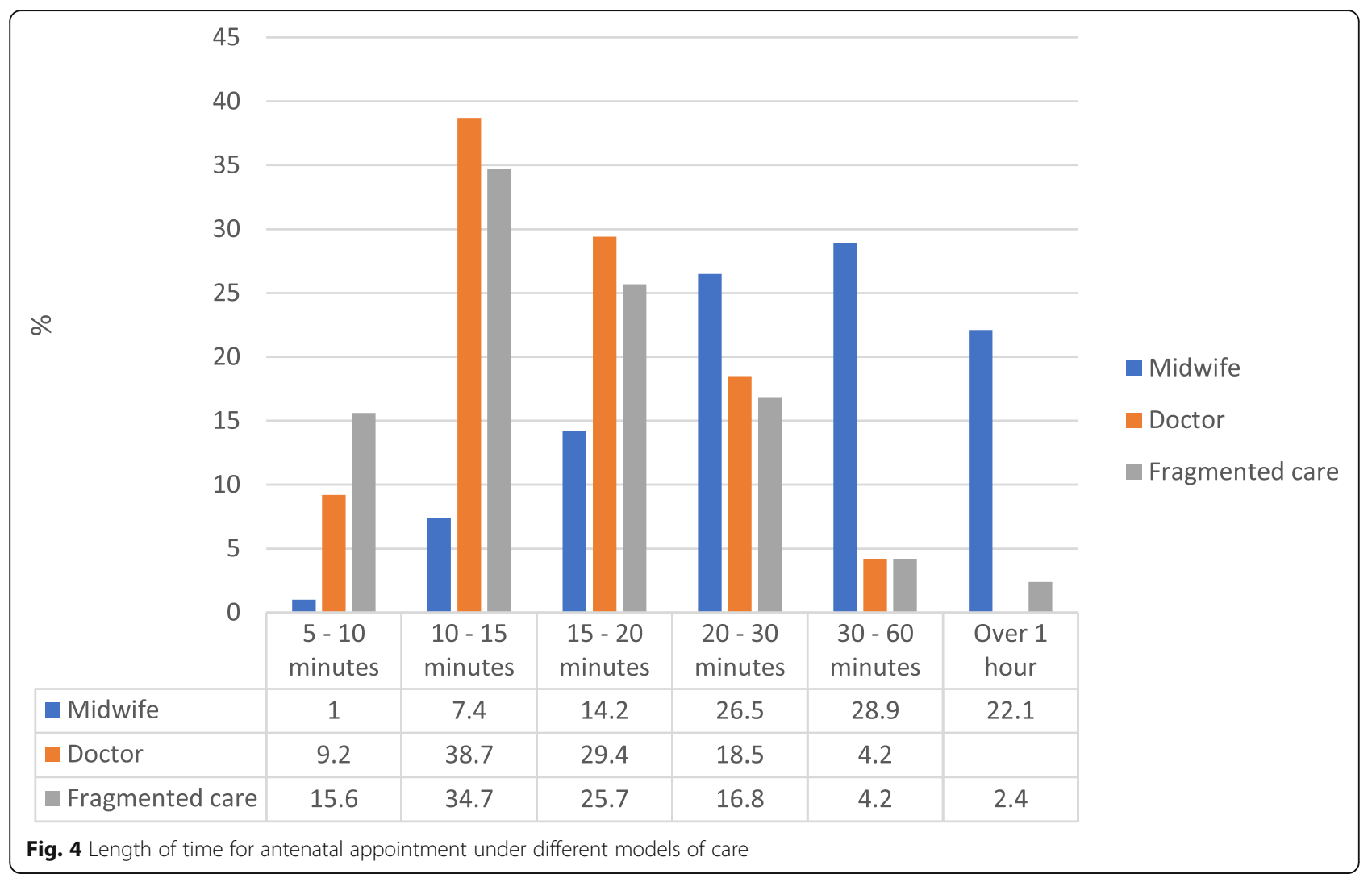

\section{Confidence}

Women were aware of how confident their healthcare providers were in their ability to have a VBAC, with higher percentages of women feeling that midwives instilled more confidence when compared to doctors, or when cared for under fragmented care models. CarolanOlah, Kruger [53] (2015) explored midwives views on the factors that facilitate normal birth and discovered that experience, confidence and a passion for normal birth were important factors. This was seen as stemming from a belief in the woman's ability to have a vaginal birth [54]. Continuity of care with a midwife has been found to increase women's confidence by: reinforcing normality [55]; helping women feel safe and secure [56, 57]; and providing choices [58]. Midwives' confidence in women results in women feeling more confident in themselves [59].

Lundgren (2015) [60] found that midwives and doctors who were confident about supporting VBAC developed this from having a shared goal to support women, and increase the woman's confidence in having a vaginal birth. A systematic review, and metasynthesis of clinician's views, of factors influencing decision-making around caesarean found that a lack of confidence from the clinician, in supporting, and promoting vaginal birth, influenced the decision to perform a caesarean [61]. Countries with higher VBAC rates demonstrate congruent positive attitudes in VBAC across professions [20] and through collaboration increase women's confidence in their ability to have a VBAC [62]. Successful implementation of methods to increase HCP confidence, through collaboration and shared belief in VBAC across professions, could benefit women planning a VBAC.

\section{Relationship}

The relationship factor explores the differences between $\mathrm{CoC}$ with a midwife and $\mathrm{CoC}$ with a doctor and fragmented care where there is limited relationship. Although both the $\mathrm{CoC}$ with a doctor and $\mathrm{CoC}$ with a midwife have the important aspect of continuity, it is the relational differences that become apparent in this study. Women who had $\mathrm{CoC}$ with a midwife felt more in control of their decision-making, more likely to have a birth plan and had higher MADM and MORi scores compared to $\mathrm{CoC}$ with a doctor. Women also felt that midwives were more confident in their ability to have a VBAC during pregnancy, or during labour, and that they received more positive support when having $\mathrm{CoC}$ from a midwife. However, $\mathrm{CoC}$ with either provider clearly scored better than fragmented care in most aspects.

Relationships between midwives or doctors and women should be based on trust, empathy and respect $[58,63,64]$ and for this to occur they require adequate time to develop [65]. Boyle et al. (2016) found women were able to form an emotional bond, and partnership 
Table 6 Active labour \& birth outcomes

\begin{tabular}{|c|c|c|c|c|c|}
\hline & $\begin{array}{l}\text { TOTAL INCLUDED } \\
\text { POPULATION } \\
N=490 \\
N(\%)\end{array}$ & $\begin{array}{l}\text { Fragmented } \\
\text { care } \\
n=167(34.1 \%) \\
n(\%)\end{array}$ & $\begin{array}{l}\text { CoC with a } \\
\text { Doctor } \\
n=119(24.3 \%) \\
n(\%)\end{array}$ & $\begin{array}{l}\text { CoC with a } \\
\text { Midwife } \\
n=204(41.6 \%) \\
n(\%)\end{array}$ & $\begin{array}{l}\text { Statistical } \\
\text { differences } \\
p \text { value }\end{array}$ \\
\hline \multicolumn{6}{|l|}{ Active Labour } \\
\hline Access active labour resources & $255(52)$ & $89(53.3)$ & $50(42)$ & $116(56.9)$ & 0.09 \\
\hline \multicolumn{6}{|c|}{ Techniques used in labour (more than 1 answer allowed) } \\
\hline Water immersion & $103(21)$ & $20(12)$ & $13(10.9)$ & $70(34.3)$ & \\
\hline Shower & $190(38.8)$ & $59(35.3)$ & $34(28.6)$ & $97(47.5)$ & \\
\hline Position changes / movement & $369(75.3)$ & $125(74.9)$ & $79(66.4)$ & $165(80.9)$ & \\
\hline Acupressure \& massage / pressure & $188(38.4)$ & $58(34.7)$ & $35(29.4)$ & $95(46.6)$ & \\
\hline Breathing techniques & $283(57.8)$ & $99(59.3)$ & $60(50.4)$ & $124(60.8)$ & \\
\hline Sterile water injections in lower back / TENS / heat & $151(30.8)$ & $42(25.1)$ & $35(29.4)$ & $74(36.3)$ & \\
\hline Some other technique & $16(3.3)$ & $7(4.2)$ & $1(0.8)$ & $8(3.9)$ & \\
\hline None & $36(7.3)$ & $16(9.6)$ & $12(10.1)$ & $8(3.9)$ & \\
\hline \multicolumn{6}{|c|}{ Pain medication used in labour (more than 1 answer allowed) } \\
\hline Epidural / spinal & $97(19.8)$ & $37(22.2)$ & $25(21)$ & $35(17.2)$ & \\
\hline Epidural / spinal (as going to caesarean) & $43(7.9)$ & $14(8.4)$ & $12(10.1)$ & $17(8.3)$ & \\
\hline Narcotics & $49(10)$ & $25(15)$ & $9(7.6)$ & $15(7.4)$ & \\
\hline Nitrous oxide & $192(39.2)$ & $74(44.3)$ & $44(37)$ & $74(36.3)$ & \\
\hline Local anaesthetic & $86(17.6)$ & $30(18)$ & $28(23.5)$ & $28(13.7)$ & \\
\hline Pain medication not listed & $27(5.5)$ & $17(10.2)$ & $2(1.7)$ & $8(3.9)$ & \\
\hline Did not use any & $120(24.5)$ & $32(19.2)$ & $16(13.4)$ & $72(35.3)$ & \\
\hline Mode of birth & & & & & 0.002 \\
\hline VBAC & $325(66.3)$ & $111(66.5)$ & $73(61.3)$ & $141(69.1)$ & \\
\hline Scheduled caesarean before labour & $26(5.3)$ & $11(6.6)$ & $13(10.9)$ & $2(1)$ & \\
\hline Repeat Caesarean during labour & $71(14.5)$ & $25(15)$ & $13(10.9)$ & $33(16.2)$ & \\
\hline Missing & $68(13.9)$ & $20(12)$ & $20(16.8)$ & $28(13.7)$ & \\
\hline Birth positions (325) & & & & & $\leq 0.001$ \\
\hline Waterbith & $37(11.4)$ & $6(5.4)$ & $2(2.7)$ & $29(20.6)$ & \\
\hline Kneeling / all fours & $48(14.8)$ & $20(18)$ & $6(8.2)$ & $22(15.6)$ & \\
\hline Semi-recumbent & $59(18.2)$ & $26(23.4)$ & $22(30.1)$ & $11(7.8)$ & \\
\hline Lateral & $30(9.2)$ & $8(7.2)$ & $7(9.6)$ & $15(10.6)$ & \\
\hline Standing & $10(3.1)$ & $2(2.7)$ & $2(2.7)$ & $5(3.5)$ & \\
\hline Squatting / birth stool & $11(3.4)$ & $2(1.8)$ & $2(2.7)$ & $7(4.9)$ & \\
\hline Lying on back & $105(32.3)$ & $36(32.4)$ & $30(41.1)$ & $39(27.7)$ & \\
\hline Birth position not listed & $23(7.1)$ & $9(8.1)$ & $1(1.4)$ & $13(9.2)$ & \\
\hline Missing & $2(0.6)$ & $1(0.9)$ & $1(1.4)$ & $0(0)$ & \\
\hline Upright birth (325) & $112(34.5)$ & $35(31.5)$ & $13(17.8)$ & $64(45.4)$ & $\leq 0.001$ \\
\hline
\end{tabular}

relationship with midwives at a birthing centre, due to having more time at appointments [66]. Leap (2010) identified that a two-way relationship of trust between midwife and woman evolved over time [58]. Focus groups of midwives expressed the importance of adequate time to develop trust and rapport [67]. During appointments within a midwifery $\mathrm{CoC}$ model, less time is wasted on the woman repeating her story and instead time can be focused on individualised support and care provision [68]. A study exploring midwife-woman interactions using video ethnography found $\mathrm{CoC}$ midwives were more likely to use relational conversations with women, where they focused on discussing and "storytelling", rather than telling women what to do and this was 
enhanced through the connection and familiarity [63]. Similarly, an observational study from Japan compared women who had midwife led care versus doctor led care and found that women who had longer appointment times with a midwife had significantly higher satisfaction with care scores [69].

The length of time for antenatal appointments across the $\mathrm{CoC}$ options shows how midwives' appointments were significantly longer than $\mathrm{CoC}$ with a doctor, or in fragmented care, yet it is surprising that despite the longer appointment times, studies exploring $\mathrm{CoC}$ models report that $\mathrm{CoC}$ with a midwife is comparatively more cost effective for health services [70-72].

\section{Active labour}

This study revealed that women who accessed $\mathrm{CoC}$ with a midwife were significantly more likely to have an active and upright labour and birth, and to have a water birth. This supports previous research from the US comparing intrapartum care and experiences of women with obstetric or midwifery care [73-76]. The 2019 US study of 2539 women found that women who had a midwife attend their births had significantly fewer medical interventions during labour and birth and were more likely to use non-pharmacological comfort measures during labour and birth [73].

\section{Limitations}

Although this study was a national study and received responses from women in all states and territories the numbers were still relatively low. The recruitment to the survey used a non-probability based, self-selected, sample of women using social media. The limitations to this design are due to the potential lack of generalisability and selection bias caused by individuals choosing to participate in the survey [45], the anonymity of the respondents makes it difficult to know if the respondents reflect the experiences of all women planning a VBAC, especially of women who chose not to respond to the survey. Distribution of the survey was achieved via social media and this may be a limitation for women who choose not to use social media and for those who have no or limited access to the web-based survey. Women who have previously planned a VBAC and had a repeat caesarean may not be members of VBAC specific social media groups or birthing groups and may not have been aware of this survey. Paid adverts were used to attempt to reach women no longer active in these groups and targeted women aged 18-45 years living in Australia.

The majority of the survey focused on women's experiences of planning a VBAC however, there were 68 respondents who didn't respond to the birth outcome question. Analysis that identifies women who had a VBAC or had a repeat caesarean did not include this missing data.
Most of the survey respondents were born in Australia, and were university educated with high incomes, suggesting a well-educated and well-resourced population. It is estimated that only $8 \%$ of women access midwifery $\mathrm{CoC}$ models in Australia [27], however $42 \%$ of women in this study identified having midwifery $\mathrm{CoC}$. Further research is required from the wider Australian community including women from Aboriginal and/or Torres Strait Islander and culturally and linguistically diverse communities.

\section{Implications for practice}

This study highlights the benefits of $\mathrm{CoC}$ models, specifically $\mathrm{CoC}$ with a midwife. Current continuity of midwifery care models should be extended to include women seeking a VBAC and more midwifery continuity of care models should be implemented for women planning a VBAC.

\section{Conclusion}

This study explored the experiences of planning a VBAC in a non-probability based, self-selected, sample of women recruited through social media. The study compared women's experiences between $\mathrm{CoC}$ with a midwife, $\mathrm{CoC}$ with a doctor or fragmented care. Women found VBAC less traumatic than their previous caesarean and those who had $\mathrm{CoC}$ with a midwife were more likely to feel in control of the decisionmaking, feel that their midwife was confident in their ability to have a VBAC and to receive positive support. Women who had $\mathrm{CoC}$ with a midwife were also more likely to have been active in labour, experience water immersion and have an upright birthing position. There needs to be a focus on increasing shared belief and confidence in VBAC across professions and an expansion of midwifery led continuity of care models for women seeking a VBAC.

\section{Supplementary information}

Supplementary information accompanies this paper at https://doi.org/10. 1186/s12884-020-03075-8.

Additional file 1. Survey questions. A copy of the survey questions

used in this study.

Abbreviations

VBAC: Vaginal birth after caesarean; CoC: Continuity of Care; MADM: Mother's Autonomy in Decision Making; MORi: Mothers on Respect index;

Frag: Fragmented care; Dr.: Doctor; MW: Midwife

\section{Acknowledgments}

"Not applicable"

Authors' contributions

All authors have read and approved the manuscript. HK, HD, VS \& EB designed the survey. HK and HD distributed the survey. HK, HD \& LP undertook data analysis. HK, HD, VS, EB, WK and LP were involved in interpreting data, writing, reading and approving the final manuscript.

Funding

There was no funding for this study. 


\section{Availability of data and materials}

The data that support the findings of this study are available on request from the corresponding author HK. The data are not publicly available due to them containing information that could compromise research participant privacy/consent

\section{Ethics approval and consent to participate}

The study was approved by the Western Sydney University Human Research Ethics Committee, approval code H11890. Participants gave written consent.

\section{Consent for publication}

"not applicable".

\section{Competing interests}

The authors declare that they have no competing interests.

\section{Author details}

'School of Nursing and Midwifery, Western Sydney University, Locked Bag 1797, Penrith, NSW 2751, Australia. ${ }^{2}$ Amsterdam University Medical Centers, Department of Midwifery Science, Amsterdam Public Health Research Institute, Amsterdam, Netherlands. ${ }^{3}$ School of Environmental Sciences, Charles Sturt University, Bathurst, Australia.

\section{Received: 15 February 2020 Accepted: 23 June 2020}

\section{Published online: 30 June 2020}

\section{References}

1. ACOG. Practice Bulletin No. 184 Vaginal Birth After Cesarean Delivery. The American College of Obstetricians and Gynecologists; 2017.

2. AlHW. Australia's mothers and babies 2017-in brief. Canberra: Australian Institute of Health and Welfare; 2019. Contract No.: Cat. no. PER 100.

3. Martin Hamilton B, Oserman M, Driscoll A, Drake P. Births: Final data for 2016. Hyattsville: National Centre for Health Statistics; 2018. Report No.: 1.

4. Project E-P. European perinatal Health report. Core indicators of the health and care of pregnant women and babies in Europe in 2015; 2018

5. Centre for Epidemiology and Evidence. New South Wales Mothers and Babies 2018. Sydney: NSW Ministry of Health; 2019.

6. Boerma T, Ronsmans C, Melesse DY, Barros AJD, Barros FC, Juan L, et al. Global epidemiology of use of and disparities in caesarean sections. Lancet. 2018;392(10155):1341-8

7. Miller S, Abalos E, Chamillard M, Ciapponi A, Colaci D, Comandé D, et al. Beyond too little, too late and too much, too soon: a pathway towards evidence-based, respectful maternity care worldwide. Lancet. 2016; 388(10056):2176-92

8. Betrán AP, Temmerman M, Kingdon C, Mohiddin A, Opiyo N, Torloni MR et al. Interventions to reduce unnecessary caesarean sections in healthy women and babies. Lancet. 2018;392(10155):1358-68.

9. NSW Health. Maternity - Towards Normal Birth in NSW. Sydney: NSW Department of Health, Division SD; 2010. 29/06/2010.

10. Rietveld AL, van Exel NJA, Cohen de Lara MC, de CJM G, Teunissen PW. Giving birth after caesarean: Identifying shared preferences among pregnant women using Q methodology. Women Birth. 2019.

11. Wise MR, Sadler L, Shorten B, van der Westhuizen K, Shorten A. Birth choices for women in a 'Positive Birth after Caesarean' clinic: Randomised trial of alternative shared decision support strategies. Aust N Z J Obstet Gynaecol. 2019;59:684.

12. Kingdon C, Downe S, Betran AP. Women's and communities' views of targeted educational interventions to reduce unnecessary caesarean section: a qualitative evidence synthesis. Reprod Health. 2018:15(1):130

13. Gilbert S, Grobman A, Landon MB, Spong CY, Rouse DJ, Leveno KJ, Varner MW, Caritis ST, Meis PJ, Sorokin Y, Carpenter M, O'Sullivan MJ, Sibai BM, Thorp JM, Ramin SM, Mercer BM. Elective repeat cesarean delivery compared with spontaneous trial of labour after a prior cesarean delivery: a propensity score analysis. Am J Obstet Gynecol. 2012;206(311):1-9.

14. Korb D, Goffinet F, Seco A, Chevret S, Deneux-Tharaux C, Group ES. Risk of severe maternal morbidity associated with cesarean delivery and the role of maternal age: a population-based propensity score analysis. CMAJ. 2019; 191(13):E352-E60

15. Mooney SS, Hiscock R, Clarke IDA, Craig S. Estimating success of vaginal birth after caesarean section in a regional Australian population: validation of a prediction model. Aust N Z J Obstet Gynaecol. 2019;59(1):66-70.
16. Lyckestam Thelin I, Lundgren I, Nilsson C. To challenge oneself as a childbearing woman-the lived experience of vaginal birth after caesarean section in Sweden. Int J Qual Stud Health Well-being. 2019;14(1):1605784.

17. Keedle H, Schmied V, Burns E, Dahlen HG. A narrative analysis of women's experiences of planning a vaginal birth after caesarean (VBAC) in Australia using critical feminist theory. BMC pregnancy and childbirth. 2019:19(1):142.

18. Wu Y, Kataria Y, Wang Z, Ming W-K, Ellervik C. Factors associated with successful vaginal birth after a cesarean section: a systematic review and meta-analysis. BMC Pregnancy Childbirth. 2019;19(1):360.

19. Knight HE, Gurol-Urganci I, van der Meulen JH, Mahmood TA, Richmond $\mathrm{DH}$, Dougall A, et al. Vaginal birth after caesarean section: a cohort study investigating factors associated with its uptake and success. BJOG. 2014; 121(2):183-92.

20. Lundgren I, Morano S, Nilsson C, Sinclair M, Begley C. Cultural perspectives on vaginal birth after previous caesarean section in countries with high and low rates - A hermeneutic study. Women Birth; 2019

21. Darling E. Vaginal birth after cesarean section: outcomes of women receiving midwifery Care in Ontario. Can J Midwifery Res Pract. 2011;10(1): 9-19.

22. Zhang T, Liu C. Comparison between continuing midwifery care and standard maternity care in vaginal birth after cesarean. Pak J Med Sci. 2016; 32(3):711-4.

23. Keedle S. V, Burns E, Dahlen H. the journey from pain to power: a metaethnography on women's experiences of vaginal birth after caesarean. Women and Birth. 2018;31(1):69-79.

24. Sandall J, Soltani H, Gates S, Shennan A, Devane D. Midwife-led continuity models versus other models of care for childbearing women. Cochrane Database Syst Rev. 2016;4

25. Chapman A, Nagle C, Bick D, Lindberg R, Kent B, Calache J, et al. Maternity service organisational interventions that aim to reduce caesarean section: a systematic review and meta-analyses. BMC Pregnancy Childbirth. 2019;19(1): 206.

26. Rosenstein MG, Nijagal M, Nakagawa S, Gregorich SE, Kuppermann M. The association of expanded access to a collaborative midwifery and laborist model with cesarean delivery rates. Obstet Gynecol. 2015;126(4):716.

27. Dawson K, McLachlan H, Newton M, Forster D. Implementing caseload midwifery: exploring the views of maternity managers in Australia - a national cross-sectional survey. Women Birth. 2016;29(3):214-22.

28. Wilkes E, Gamble J, Adam G, Creedy DK. Reforming maternity services in Australia: outcomes of a private practice midwifery service. Midwifery. 2015; 31(10):935-40.

29. Creswell JW, Plano Clark VL. In: Plano Clark VL, editor. Designing and conducting mixed methods research. 2nd ed. Los Angeles: SAGE Publications; 2011

30. Vedam S, Stoll K, Martin K, Rubashkin N, Partridge S, Thordarson D, et al. The Mother's autonomy in decision making (MADM) scale: patient-led development and psychometric testing of a new instrument to evaluate experience of maternity care. PLoS One. 2017;12(2):e0171804.

31. Vedam S, Stoll K, Rubashkin N, Martin K, Miller-Vedam Z, Hayes-Klein H, et al. The mothers on respect (MOR) index: measuring quality, safety, and human rights in childbirth. SSM Popul Health. 2017:3:201-10.

32. Vedam S, Stoll K, McRae DN, Korchinski M, Velasquez R, Wang J, et al. Patient-led decision making: measuring autonomy and respect in Canadian maternity care. Patient Educ Couns. 2019;102(3):586-94.

33. Feijen-de Jong El, van der Pijl M, Vedam S, Jansen D, Peters LL. Measuring respect and autonomy in Dutch maternity care: applicability of two measures. Women and Birth. 2019.

34. Ropers-Huilman R, Winters KT. Feminist research in higher education. J High Educ. 2011;82(6):667-90

35. Wallen GR, Saygbe JN, Brooks AT, McClurkin M, Thomas S, Powell-Wiley TM. Engaging community leaders in the development of a cardiovascular Health behavior survey using focus group-based cognitive interviewing Health services insights. 2017;10:1178632917701123.

36. Willis GB. Analysis of the cognitive interview in questionnaire design: Oxford University press; 2015

37. Peterson $\mathrm{CH}$, Peterson NA, Powell $\mathrm{KG}$. Cognitive interviewing for item development: validity evidence based on content and response processes. Meas Eval Couns Dev. 2017:50(4):217-23.

38. Willis GB. Cognitive interviewing a tool for improving questionnaire design. Sage Research Methods O, editor. Thousand Oaks, Calif. London: Thousand Oaks, Calif. London : SAGE; 2005. 
39. Zoom. Zoom Video Communications, Inc. San Jose, California: Zoom Video Communications, Inc.; 2011 [Version: 4.5.2::[.

40. RANZCOG. Birth after previous caesarean section. The Royal Australian and New Zealand College of Obstetricians and Gynaecologists; 2015.

41. Motomura. K, Ganchimeg T, Nagata C, Ota E, Vogel J, Betran A, et al. Incidence and outcomes of uterine rupture among women with prior caesarean section: WHO Multicountry Survey on Maternal and Newborn Health. Scientific reports. 2017;7:44093.

42. Halperin EM, Moore CD, Hannah JW. Classical versus low-segment transverse incision for preterm caesarean section: maternal complications and outcome of subsequent pregnancies. Obstetrical \& Gynecological Survey. 1989;44(6):454-5.

43. Landon MB, Lynch CD. Optimal timing and mode of delivery after cesarean with previous classical incision or myomectomy: a review of the data. Semin Perinatol. 2011;35(5):257-61.

44. Qualtrics (.) Provo, Utah, USA2019 [Available from: http://www.qualtrics.com.

45. Fricker RD. Sampling methods for web and e-mail surveys. The SAGE handbook of online research methods. 2008:195-216.

46. IPCC. Climate Change 2013: The physical science basis: Working group I contribution to the fifth assessment report of the Intergovernmental Panel on Climate Change. Intergovernmental Panel On Climate Change, editor: Cambridge University Press; 2014.

47. Bohren M, Vogel J, Hunter E, Lutsiv O, Makh S, Souza J, et al. The Mistreatment of Women during Childbirth in Health Facilities Globally: A Mixed-Methods Systematic Review. PLoS Medicine. 2015;12(6).

48. Bohren MA, Mehrtash H, Fawole B, Maung TM, Balde MD, Maya E, et al. How women are treated during facility-based childbirth in four countries: a cross-sectional study with labour observations and community-based surveys. Lancet. 2019.

49. Simpson M, Schmied V, Dickson C, Dahlen HG. Postnatal post-traumatic stress: an integrative review. Women Birth. 2018;31(5):367-79.

50. Downe S, Finlayson K, Oladapo OT, Bonet M, Gulmezoglu AM. What matters to women during childbirth: a systematic qualitative review. PLoS One. 2018;13(4):e0194906

51. Elmir R, Schmied, V., Wilkes, L., Jackson, D. Women's perception and experiences of a traumatic birth: a meta-ethnography. Journal of Advanced Nursing. 2010;Jan: Review Paper:2142-53.

52. McKenna JA, Symon AG. Water VBAC: exploring a new frontier for women's autonomy. Midwifery. 2014;30(1):e20-5.

53. Carolan-Olah M, Kruger G, Garvey-Graham A. Midwives' experiences of the factors that facilitate normal birth among low risk women at a public hospital in Australia. Midwifery. 2015;31(1):112-21.

54. Keedle $\mathrm{H}$. Women's reasons for and experiences of having a homebirth following a previous caesarean experience. Sydney: Western Sydney University; 2015

55. Dove S, Muir-Cochrane E. Being safe practitioners and safe mothers: a critical ethnography of continuity of care midwifery in Australia. Midwifery. 2014.

56. Fenwick J, Brittain H, Gamble J. Australian private midwives with hospital visiting rights in Queensland: structures and processes impacting clinical outcomes. Women Birth. 2017;30(6):497-505.

57. Davison C, Hauck YL, Bayes SJ, Kuliukas LJ, Wood J. The relationship is everything: Womens reasons for choosing a privately practising midwife in Western Australia. Midwifery. 2015;31(8):772-8.

58. Leap S. J, Buckland S, Huber U. journey to confidence: Women's experiences of pain in labour and relational continuity of care. Journal of Midwifery \& Women's Health. 2010;55(3):234-42.

59. Avery MD, Saftner MA, Larson B, Weinfurter EV. A systematic review of maternal confidence for physiologic birth: characteristics of prenatal care and confidence measurement. J Midwifery Womens Health. 2014;59(6):58695.

60. Lundgren, Smith V, Nilsson C, Vehvilainen-Julkunen K, Nicoletti J, Devane D, et al. Clinician-centred interventions to increase vaginal birth after caesarean section (VBAC): a systematic review. BMC pregnancy and childbirth. 2015; 15(1):16.

61. Panda S, Begley C, Daly D. Clinicians' views of factors influencing decisionmaking for caesarean section: a systematic review and metasynthesis of qualitative, quantitative and mixed methods studies. PLoS One. 2018;13(7): e0200941.

62. Lundgren I, van Limbeek E, Vehvilainen-Julkunen K, Nilsson C. Clinicians' views of factors of importance for improving the rate of VBAC (vaginal birth after caesarean section): a qualitative study from countries with high VBAC rates. BMC pregnancy and childbirth. 2015;15(1):196.

63. Teate A. From worry to hope: an ethnography of midwife-woman interactions in the antenatal appointment. Sydney: Western Sydney University; 2018

64. Dahlberg U, Aune I. The woman's birth experience-the effect of interpersonal relationships and continuity of care. Midwifery. 2013;29(4):40715.

65. Perriman N, Davis DL, Ferguson S. What women value in the midwifery continuity of care model: a systematic review with meta-synthesis. Midwifery. 2018;62:220-9.

66. Boyle S, Thomas H, Brooks F. Women's views on partnership working with midwives during pregnancy and childbirth. Midwifery. 2016;32:21-9.

67. Browne J, O'Brien M, Taylor J, Bowman R, Davis D. 'You've got it within you': the political act of keeping a wellness focus in the antenatal time. Midwifery. 2014;30(4):420-6.

68. McCourt C, Stevens T. Continuity of carer-what does it mean and does it matter to midwives and birthing women? Canadian Journal of Midwifery Research and Practice. 2006;4(3):10-20.

69. lida M, Horiuchi S, Nagamori K. A comparison of midwife-led care versus obstetrician-led care for low-risk women in Japan. Women and Birth. 2014; 27(3):202-7.

70. Attanasio LB, Alarid-Escudero F, Kozhimannil KB. Midwife-led care and obstetrician-led care for low-risk pregnancies: A cost comparison. Birth. 2019;0(0)

71. Callander EJ, Topp S, Fox H, Corscadden L. Out-of-pocket expenditure on health care by Australian mothers: lessons for maternal universal health coverage from a long-established system. Birth. 2019.

72. Toohill J, Turkstra E, Gamble J, Scuffham PA. A non-randomised trial investigating the cost-effectiveness of midwifery group practice compared with standard maternity care arrangements in one Australian hospital. Midwifery. 2012;28(6):e874-9.

73. Declercq ER, Belanoff C, Sakala C. Intrapartum Care and Experiences of Women with Midwives Versus Obstetricians in the Listening to Mothers in California Survey. Journal of Midwifery \& Women's Health. 2019;0(0).

74. Cragin L, Kennedy HP. Linking obstetric and midwifery practice with optimal outcomes. J Obstet Gynecol Neonatal Nurs. 2006;35(6):779-85.

75. Walsh D, Devane D. A metasynthesis of midwife-led care. Qual Health Res. 2012;22(7):897-910.

76. Fore MS, Allshouse AA, Carlson NS, Hurt KJ. Outcomes of trial of labor after cesarean birth by provider type in low-risk women. Birth; 2019.

\section{Publisher's Note}

Springer Nature remains neutral with regard to jurisdictional claims in published maps and institutional affiliations.

Ready to submit your research? Choose BMC and benefit from:

- fast, convenient online submission

- thorough peer review by experienced researchers in your field

- rapid publication on acceptance

- support for research data, including large and complex data types

- gold Open Access which fosters wider collaboration and increased citations

- maximum visibility for your research: over $100 \mathrm{M}$ website views per year

At $\mathrm{BMC}$, research is always in progress.

Learn more biomedcentral.com/submissions 